\title{
Effect of smoke exhaust openings placement direction of tunnel ceiling mechanical exhaust system
}

\author{
Yu Li, Shuang Wang \\ Department of Rord and Railway Engineering, School of Civil and Safety Engineering \\ DaLian JiaoTong University \\ Dalian, China \\ 1610831806@qq.com
}

\begin{abstract}
The numerical mode was constructed on the basis of a 7 m-length with 1/10th scale model of subway platform channel. Firstly, the temperature and thickness of smoke layer under the smoke exhaust opening of different placement direction are simulated by using numerical simulation software. In this paper, the regulation of changeable temperature and thickness of smoke layer under the smoke exhaust opening is studied by changing the smoke exhaust rate.Then the Origin was used to fit the smoke layer thickness data obtained by numerical simulation. The model used the same fire heat release rate and the smoke exhaust opening size. The results show that the smoke exhaust rate of the smoke exhaust openings which are horizontally placed is larger than that of the smoke exhaust openings which are placed longitudinally. And the model for estimating the smoke layer thickness in the horizontal direction of smoke exhaust openings is $y=y_{0}+A e^{R_{0} X}$. The model for estimating the smoke layer thickness in the longitudinal direction of the smoke exhaust openings is $y=e^{a+b x+c x^{2}}$.
\end{abstract}

Keywords-FDS; smoke exhaust opening; smoke exhaust rate; placement direction; curve fitting

\section{INTRODUCTION}

Along with the accelerating process of urbanization and the rapid development of science and technology, the development and usage of long channel has achieved fast development, especially the traffic system, which is represented by the highway tunnel, the railway tunnel, the urban subway tunnel and the underground pedestrian passageway. Long channel has the characteristics of long and narrow space, limited side wall, outlet with two ends and forced ventilation. These characteristics make it difficult to study the smoke exhaust problem during the fire. Among them, the smoke exhaust opening is one of the most difficult focus of the researches about the problem of smoke exhaust in the tunnel. In this regard, some scholars studied the problem of smoke exhaust opening from the smoke exhaust efficiency, smoke exhaust opening distance and other aspects. Vauquelin [1] studies the factors that affect the efficiency of mechanical smoke exhaust. Rie Dong-Ho [2],Yuan Feng-Dong [3] use numerical simulation method to analyze and optimize the mechanical smoke exhaust effect of subway station under different ventilation modes. Yaqiang Jiang ${ }^{[4]}$ puts forward that there is a transition zone and a complete absorption zone, and the efficiency of mechanical smoke exhaust decreases with the increase of the plugholing degree. Qiang Wang ${ }^{[5]}$ proposes the smoke back-layering can be significantly affected by the upstream openings arrangement in tunnel fires.Fumiaki Ura [6] proposes that the smoke flowing along the ceiling thinned out and quickly became zero when a fire occurred in the shallow urban road tunnel with roof openings at a $15 \%$ opening ratio. Xuepeng Jiang [7] pointes out that more distant the smoke exhaust opening from the fire is, the more prone is to plugholing. Chongqing Cai [8] pointed out that the greater distance between the smoke exhaust openings is, the smaller the smoke exhaust rate of plug holing is. In this paper, by changing the smoke exhaust rate, the temperature and the smoke layer thickness under the smoke exhaust opening of different placement direction are simulated. The relationship among the smoke exhaust rate, the temperature and the smoke exhaust rate, the thickness of the smoke layers is studied. And by using model fitted by Origin, the thickness of the smoke under the any rate can be obtained.

\section{NUMERICAL SIMULATION STUDY}

\section{A. Simulation Test Model}

This paper used the PyroSim fire dynamic simulation software(FDS) to establish a fire model that was developed by National Institute of standards and technology (NIST). The movement of smoke in the fire, the temperature and the smoke layer height were predicted by this software.

In order to study the development of fire, a lot of fire science researchers have established different models of tunnel fire tests. The physical model used in this paper is based on the small-scale channel model of the State Key Laboratory of fire of the University of science and technology of China [9]. The ratio of the model to the prototype is $1 / 10$. The tunnel model is $7 \mathrm{~m}$ long, $1.5 \mathrm{~m}$ wide and $0.6 \mathrm{~m}$ tall. As shown in Fig. 1,the right end of channel opened and the left closed.The distance between the center line of smoke exhaust opening and that of the left channel is $0.8 \mathrm{~m}$. The fire size is $20 \mathrm{~cm} \times 20 \mathrm{~cm}$ and its center line distance from the left channel is $2.2 \mathrm{~m}$.

At home and abroad, the fire heat release rate of $2 \mathrm{MW}$ is 


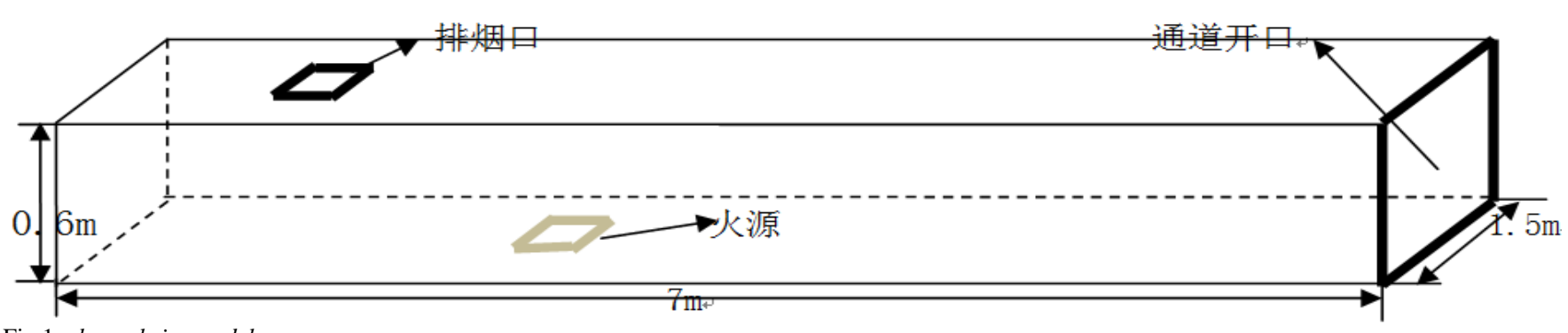

Fig.1. channel size model

usually chosen as the research of subway fire [10]. For the sake of conservatism, it is set as 4MW in this paper. According to the Froude similarity criterion [11], The fire heat release rate of the small size experimental model is $12.64 \mathrm{~kW}$ (Equation (1) ,"m” means "model","F" means "fact") . It is assumed that the smoke exhaust opening opens when the fire is $60 \mathrm{~s}$ in the actual tunnel fire. So according to the Froude similarity criterion, the model is set up to open the smoke exhaust opening when the fire occurs in the $19 \mathrm{~s}$.

$$
Q_{m}=Q_{F}\left(\frac{1}{10}\right)^{\frac{5}{2}}=12.64 \mathrm{~kW}
$$

\section{B. Design of Simulation Test Conditions}

Table 1 is the operating mode of this simulated test and it includs 72 groups. Each set of condition has different smoke exhaust rate or the placement direction of smoke exhaust openings . Each column of data indicates the condition number, the fire heat release rate, the size of the smoke exhaust opening, the opening time of the smoke exhaust opening, the calculation time and the smoke exhaust rate. Horizontal direction of smoke exhaust openings is the long side placed horizontally along the tunnel. Longitudinal direction of the smoke exhaust openings is the long side placed longitudinally along the tunnel.

\section{Monitoring Device}

The measure points of temperature and smoke layer height in the experimental model are set up. One of measure points of smoke layer height is set at the position of $y=0.75 \mathrm{~m}$ 、 $\mathrm{x}=0.8 \mathrm{~m} .14$ thermocouples are set along $\mathrm{Z}$ direction with $0.025 \mathrm{~m}$ as the spacing at the position of $\mathrm{y}=0.75 \mathrm{~m}$ 、 $\mathrm{x}=0.8 \mathrm{~m}$.And the highest point is $0.025 \mathrm{~m}$ away from the roof. The specific arrangement is shown in Fig. 2.

\section{RESULTS AND ANALYSIS}

\section{A. Temperature Distribution}

Fig. 3 is the temperature section of the center of the channel. It reflects the change of the positive center temperature in the channel under different smoke exhaust rate. From the figure ,the whole process of plugholing can be seen directly. When the smoke exhaust rate is small, the smoke exhaust opening are only full of smoke. With the smoke exhaust rate gradually increased, the smoke exhaust opening began to exhaust air. Until the smoke exhaust rate increased to a certain value, the smoke exhaust opening is full of air instead of smoke.

Fig. 4 is the smoke exhaust rate-temperature curve of each measuring point under the $20 \mathrm{~cm} \times 35 \mathrm{~cm}$ smoke exhaust opening of horizontal position. The temperature is indicated by $T_{i} / T_{\text {ref }} . T_{i}$ is temperature of each measuring point for each condition. $T_{r e f}$ is maximum temperature of each condition. From figure it can be seen that,when the smoke exhaust rate, $V_{e}$ is limited with $0.01 \mathrm{~m}^{3} / \mathrm{s}$ and $0.09 \mathrm{~m}^{3} / \mathrm{s}$, the temperature curve of the 6 monitoring points which is between $0.25 \mathrm{~m}$ and $0.375 \mathrm{~m}$ and below the smoke exhaust opening begin to be gentle.And it gradually tended to a fixed value. This region of the curve is called a plugholing transition region. This is due to a sunken area below the smoke exhaust opening after the plugholing. Each monitoring point in the area is exposed to air and its temperature is reduced to the air temperature. When the smoke exhaust rate is greater than $0.1 \mathrm{~m}^{3} / \mathrm{s}$, the smoke layer is completely plug-holing. So this area is called a full plugholing area. However, after the plugholing occurs, the temperature under the smoke exhaust

TABLE I. SIMULATION TEST CONDITIONS

\begin{tabular}{|c|c|c|c|c|c|}
\hline $\begin{array}{c}\text { Condition } \\
\text { Number }\end{array}$ & $\begin{array}{l}\text { Fire Heat Release Rate } \\
\qquad(\mathbf{k w})\end{array}$ & $\begin{array}{l}\text { Size of Smoke Exhaust } \\
\text { Vent }(\mathbf{c m} \times \mathbf{c m})\end{array}$ & $\begin{array}{c}\text { Opening Time of } \\
\text { Smoke Exhaust Vent } \\
\text { (s) }\end{array}$ & $\begin{array}{l}\text { Computing } \\
\text { Time (s) }\end{array}$ & $\begin{array}{l}\text { Smoke Exhaust Time } \\
\left(\mathrm{m}^{3} / \mathrm{s}\right)\end{array}$ \\
\hline D1 D12 & \multirow{6}{*}{12.64} & 20×35（horizontal） & \multirow{6}{*}{ 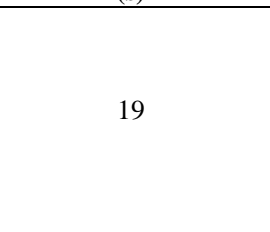 } & \multirow{6}{*}{110} & 0.01 0.12(12 groups) \\
\hline D13 D24 & & 20×35（Longitudinal） & & & 0.01 0.12(12 groups) \\
\hline D25 D36 & & 20×40（horizontal） & & & $0.01 \sim 0.12$ (12 groups) \\
\hline D37 D48 & & $20 \times 40$ (Longitudinal) & & & $0.01 \sim 0.12$ (12 groups) \\
\hline D49 D60 & & $25 \times 30$ (horizontal) & & & $0.01 \sim 0.12$ (12 groups) \\
\hline D61 D72 & & $25 \times 30$ (Longitudinal) & & & $0.01 \sim 0.12$ (12 groups) \\
\hline
\end{tabular}


opening will not be reduced to the ambient temperature, because there is still smoke are discharged from the four sides of the smoke exhaust opening.

According to the above analysis of Fig. 4 the smoke exhaust rate of plugholing under different smoke exhaust opening can be compared. Table 2 is the summary table of the fig. 4 to 9 about smoke exhaust rate of plugholing.

\section{B. Smoke Layer Thickness Distribution}

According to the measure points of the smoke layer height, the smoke layer thickness, h below the smoke exhaust opening can be indirectly obtained. When the smoke exhaust port of $20 \mathrm{~cm} \times 35 \mathrm{~cm}$ is placed horizontally, Fig. 10 . is the change curve of the smoke layer thickness with the smoke exhaust rate, $V_{e}$. The results show that the smoke layer thickness after the sunken becomes decreased with the increase of the smoke exhaust rate. But from the $V_{e}=0.1 \mathrm{~m}^{3} / \mathrm{s}$, the smoke layer thickness are reduced to zero. It means that the plugholing phenomenon will occur when the rate of smoke exhaust is greater than (equal to) $0.1 \mathrm{~m}^{3} / \mathrm{s}$. The results are basically consistent with the analytical results of Fig. 4.

According to the above analysis of Figure 10 can analogy with smoke exhaust rate of plug-holing under different smoke exhaust opening. Table 3 is the summary table of the figure 10 to 15 about smoke exhaust rate of plugholing.

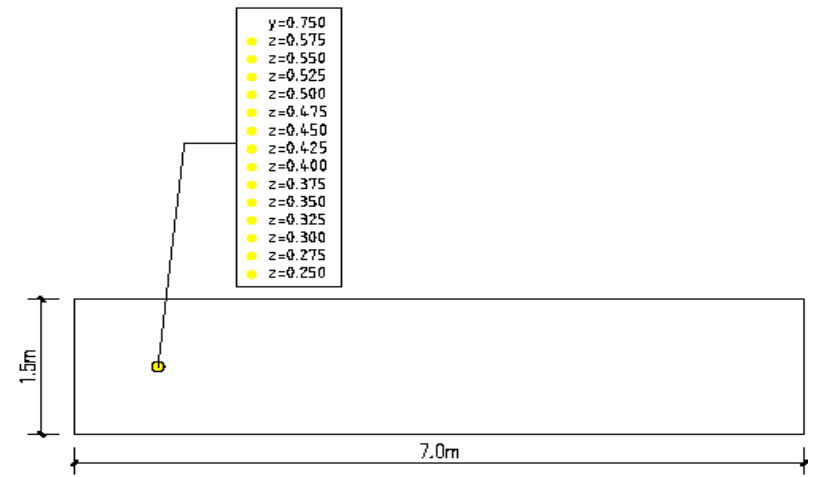

Fig.2. layout sketch map of thermocouples
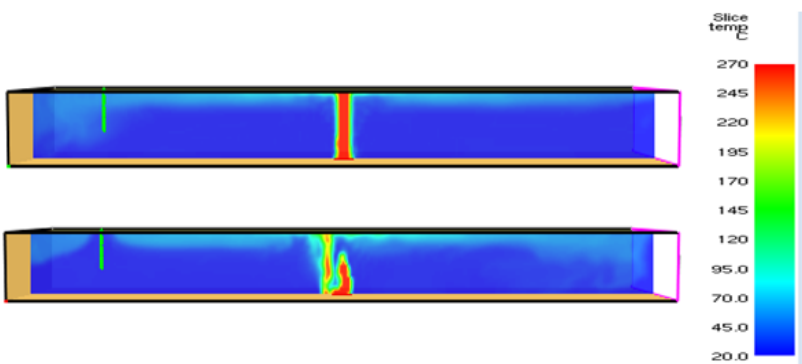

Fig.3. temperature profile at the center of the channel on different smoke exhaust rates

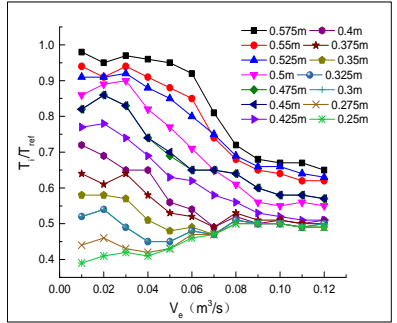

Fig.4. horizontal placement of $20 \mathrm{~cm} \times 35 \mathrm{~cm}$

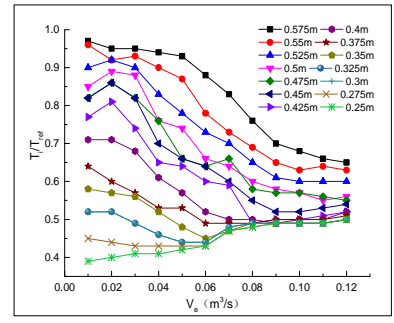

Fig.6. horizontal placement of $20 \mathrm{~cm} \times 40 \mathrm{~cm}$

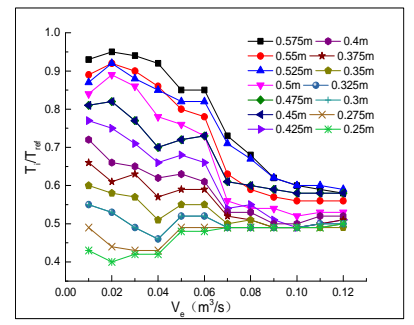

Fig.8. horizontal placement of $25 \mathrm{~cm} \times 30 \mathrm{~cm}$

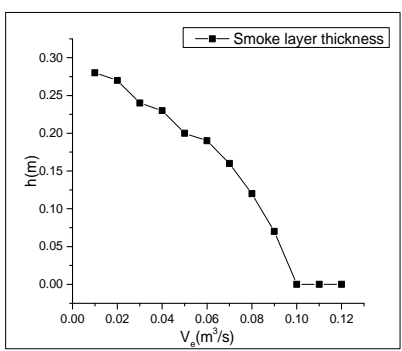

Fig.10. horizontal placement of $20 \mathrm{~cm} \times 35 \mathrm{~cm}$

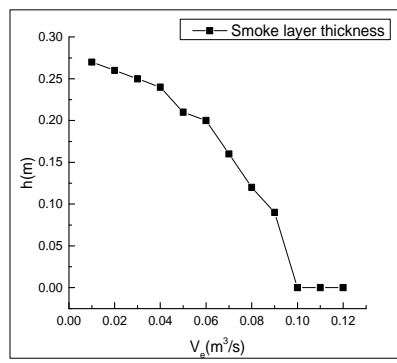

Fig.12. horizontal placement of $20 \mathrm{~cm} \times 40 \mathrm{~cm}$

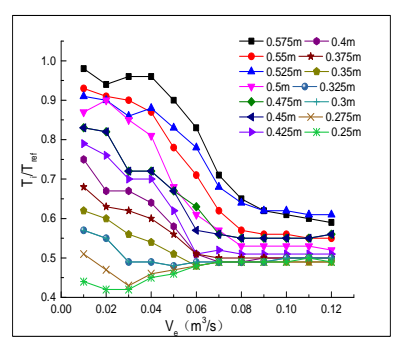

Fig.5. longitudinal placement of $20 \mathrm{~cm} \times 35 \mathrm{~cm}$

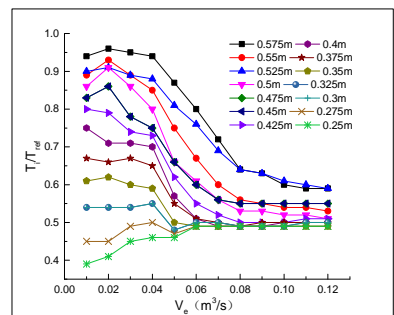

Fig.7. longitudinal placement of $20 \mathrm{~cm} \times 40 \mathrm{~cm}$

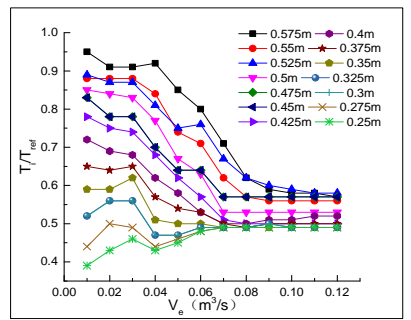

Fig.9. longitudinal placement of $25 \mathrm{~cm} \times 30 \mathrm{~cm}$

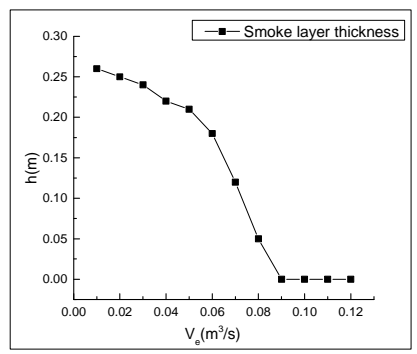

Fig.11. longitudinal placement of $20 \mathrm{~cm} \times 35 \mathrm{~cm}$

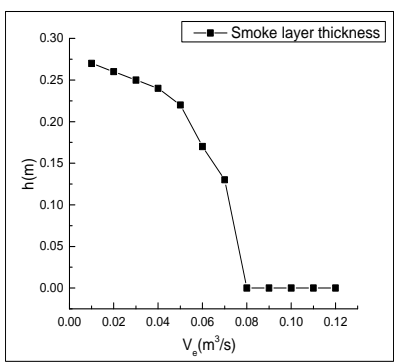

Fig.13. longitudinal placement of $20 \mathrm{~cm} \times 40 \mathrm{~cm}$ 


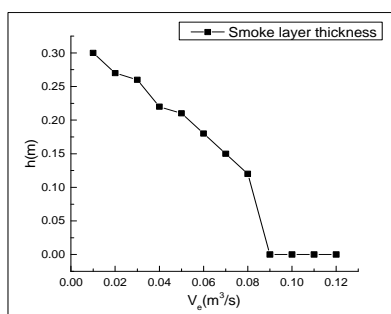

Fig.14. horizontal placement of $25 \mathrm{~cm} \times 30 \mathrm{~cm}$

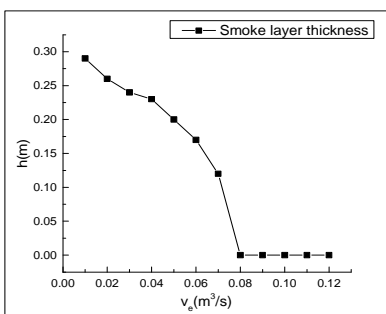

Fig.15. longitudinal placement of $25 \mathrm{~cm} \times 30 \mathrm{~cm}$

\section{Curve Fitting Model of Smoke Layer Thickness}

The Origin software [12] was used to fit the data of the 6 groups of smoke layer thickness.And then the corresponding mathematical function expression was obtained according to the fitting analysis report.

According to the scatter diagram distribution of the smoke layer thickness data, two more suitable function expressions are selected from the built-in mathematical function expression provided by Origin9. Function respectively is $y=y_{0}+A e^{R_{0} x}$ and $y=e^{a+b x+c x^{2}}$ (x represents the smoke exhaust rate, $V_{e}$; y represents the smoke layer thickness, h). Firstly,Scatter diagram of smoke layer thickness is fitted by the above two functions. The smoke layer thickness scatter diagram about the smoke exhaust rate is obtained when the $20 \mathrm{~cm} \times 35 \mathrm{~cm}$ smoke exhaust opening is placed in a horizontal position. The fitting model is shown in Figure.16,17. And then the two fitting models are compared with each other and a fitting model comparison report(Figure.18(a)) can be obtained. It can be seen from the Figure that the fitting effection of the $y=y_{0}+A e^{R_{0} x}$ model is better than that of the $y=e^{a+b x+c x^{2}}$ model.
TABLE II. A SUMMARY TABLE OF SMOKE EXHAUST RATE FROM THE POINT OF VIEW OF TEMPERATURE

\begin{tabular}{|l|l|l|}
\hline $\begin{array}{c}\text { Size of Smoke } \\
\text { Exhaust Vent } \\
(\mathbf{c m} \times \mathbf{c m})\end{array}$ & $\begin{array}{c}\text { Placement } \\
\text { Direction }\end{array}$ & $\begin{array}{c}\text { Smoke Exhaust Rate of } \\
\text { Complete plugholing }\left(\mathrm{m}^{3} / \mathrm{s}\right)\end{array}$ \\
\hline $\mathbf{2 0} \times \mathbf{3 5}$ & Horizontal & 0.10 \\
\cline { 2 - 3 } & Longitudinal & 0.08 \\
\hline \multirow{2}{20}{$\times \mathbf{4 0}$} & Horizontal & 0.09 \\
\cline { 2 - 3 } & Longitudinal & 0.08 \\
\hline $\mathbf{2 5} \times \mathbf{3 0}$ & Horizontal & 0.09 \\
\cline { 2 - 3 } & Longitudinal & 0.08 \\
\hline
\end{tabular}

The same method was adopted to fit the smoke layer thickness scatter diagram in the longitudinal position of the $20 \mathrm{~cm} \times 35 \mathrm{~cm}$ smoke exhaust opening. According to the fitting model comparison report ( Fig.18(b),the model $y=y^{a+b x+c x^{2}}$ of the fitting effect is better than the model $y=y_{0}+A e^{R_{0} x}$ of the fitting effect.

The smoke layer thickness scatter diagrams about the two sizes smoke exhaust opening of $20 \mathrm{~cm} \times 40 \mathrm{~cm}$ and $25 \mathrm{~cm} \times 30 \mathrm{~cm}$ were respectively fitted by the above methods. According to all the fitting model comparison report,when the smoke exhaust opening is placed horizontally, the fitting effect of the $y=y_{0}+A e^{R_{0} x}$ model is better than that of the $y=e^{a+b x+c x^{2}}$ model ; When the smoke exhaust opening is placed vertically, the fitting effect of the $y=e^{a+b x+c x^{2}}$ model is better than that of the $y=y_{0}+A e^{R_{0} x}$ model . Therefore, a more accurate function model is selected to fit the known data. According to the specific function expressions obtained from the fitting, the smoke layer thickness of any smoke exhaust rate can be estimated under the same conditions.

TABLE III. A SUMMARY TABLE OF SMOKE EXHAUST RATE FROM THE POINT OF VIEW OF SMOKE LAYER THICKNESS

\begin{tabular}{|c|c|c|c|}
\hline $\begin{array}{c}\text { Size of Smoke Exhaust Vent } \\
(\mathbf{c m} \times \mathbf{c m})\end{array}$ & Placement Direction & $\begin{array}{c}\text { Smoke Exhaust Rate of Complete } \\
\text { plugholing }\left(\mathrm{m}^{3} / \mathrm{s}\right)\end{array}$ & $\begin{array}{c}\text { Comparison Result of Smoke Layer } \\
\text { Thickness of Two Processes }\end{array}$ \\
\hline \multirow{2}{*}{$\mathbf{2 0 \times 3 5}$} & Horizontal & 0.10 & Basically consistent \\
\cline { 2 - 4 } & Longitudinal & $\begin{array}{c}\text { A slight deviation, but the overall } \\
\text { trend is consistent }\end{array}$ \\
\hline \multirow{2}{*}{$\mathbf{2 0 \times 4 0}$} & Horizontal & 0.09 & A slight deviation, but the overall \\
trend is consistent
\end{tabular}




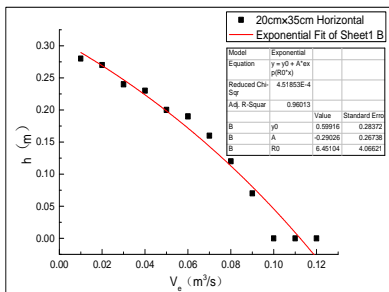

Fig.16. fitting model diagram of

$y=y_{0}+A e^{R_{0} x}$

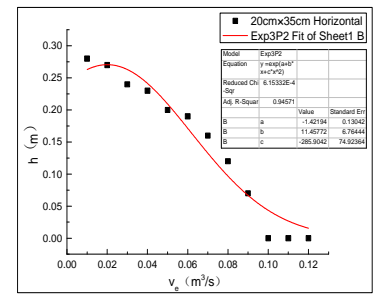

Fig.17. fitting model diagram of $y=e^{a+b x+c x^{2}}$

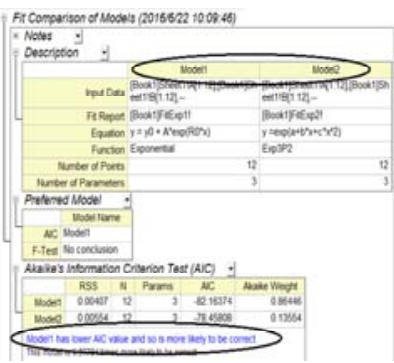

(a)

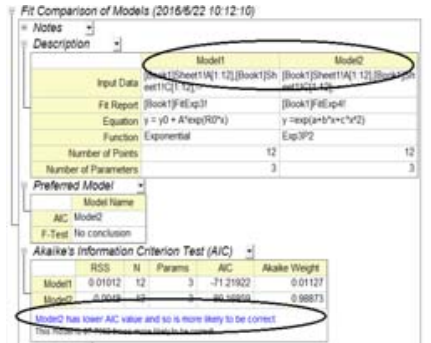

(b)
Fig.18. fitting model comparison report

\section{References}

In this paper, the FDS numerical simulation method and Origin fitting function are used to analyze the change of smoke layer temperature and thickness under the smoke exhaust opening of the different placement direction with the smoke exhaust rate. The following conclusions are obtained.

1) It is proved that the smoke exhaust rate is too large to lead to the plugholing of smoke layer. Because the phenomenon of plugholing will reduce the smoke exhaust efficiency, the actual design should avoid excessive exhaust smoke.

2) According to the different placement direction of the smoke exhaust opening, it is compared with the smoke exhaust rates of the smoke exhaust opening of the three dimensions. It is concluded that the smoke exhaust rate about the smoke exhaust opening of the horizontal direction is larger than that about the smoke exhaust opening of the longitudinal direction.

3) The simulated smoke layer thickness data are fitted by curve fitting method. Comparing with the two fitting models: when the smoke exhaust opening is placed horizontally, the $y=y_{0}+A e^{R_{0} x}$ model can be used to estimate the smoke layer thickness under different smoke exhaust rate; When the smoke exhaust opening is placed longitudinally,the $y=e^{a+b x+c x^{2}}$ model can be used to estimate the smoke layer thickness under different smoke exhaust rate.
[1] Vauquelin O,Megret O. Smoke extraction experiments in case of fire in a tunnel [J]. Fire Safety Journal, 2002, pp.525 - 533

[2] Rie Dong-Ho. A study of optimal vent mode for the smoke control of subway station fire $[\mathrm{J}]$. Tunneling and Underground Space Technology, 2006, pp.300 - 301.

[3] Yuan Feng-Dong, You Shi-Jun. CFD simulation and optimization of the ventilation for subway side-platform[J]. Tunneling and Underground Space Technology, 2007,pp. $474-482$.

[4] Yaqiang Jiang,Ran Huo,LongHua Hu. A numerical study on smoke layering pluglioling under meclianical extraction in a long channel[J].Journal of University of Science and Technology of China,2009,pp. 424-428.

[5] Qiang Wang,Fei Tang. Large eddy simulation on the effect of smoke exhaust openings arrangement on the smoke spread in tunnel fires[J].ScienceDirect,2016,pp.309-315.

[6] Fumiaki Ura, Nobuyoshi Kawabata, Futoshi Tanaka. Characteristics of smoke extraction by natural ventilation during a fire in a shallow urban road tunnel with roof openings[J]. Fire Safety Journal,2014,pp.96-106.

[7] Xuepeng Jiang,Yueming Yuan,Xu Li,et al. Experimental research on plugholing phenomenon of smoke layer in the centralized smoke exhaust rate of the tunnel[J]. Journal of Safety Science of China, 2014,pp.53-57.

[8] Chongqing Cai, Xuepeng Jiang,Yueming Yuan. Simulation of the effect of smoke exhaust opening spacing on the plugholing of the concentrated smoke layer in the tunnel[J]. Journal of safety and environment,2014,pp.95-101.

[9] ZhiSheng Xu,XuePeng Jiang.Smoke Control Engineering[M].BeiJing:mechanical Industry Press,2011

[10] Jun Yang,LiYing Yang. Discussion on subway fire scene design[J]. Journal of natural disasters,2005,pp.121-125.

[11] Quintiere J G.Scaling applications in fire research[J].Fire Safety Journal,1989,pp.3-29.

[12] WeiPing Ye,Jie Min,Kun Ren.Oringin 9.1 Technology Drawing and Data Analysis[M]. BeiJing:mechanical Industry Press,2015 